\title{
Administration of loperamide and addition of wheat bran to the diets of weaner pigs decrease the incidence of diarrhoea and enhance their gut maturation
}

\author{
Francesc Molist Gasa, Mauro Ywazaki, Arantza Gómez de Segura Ugalde, Rafael Gustavo Hermes, \\ Josep Gasa Gasó and José Francisco Pérez Hernández* \\ Grup de Nutrició, Maneig i Benestar Animal, Departament de Ciència Animal i dels Aliments, Universitat Autònoma de Barcelona, \\ Bellaterra 08193, Barcelona, Spain
}

(Received 14 May 2009 - Revised 15 September 2009 - Accepted 29 September 2009 - First published online 5 November 2009)

\begin{abstract}
The influence of fibre inclusion and transit time regulation on the performance, health status, microbial activity and population, physico-chemical characteristics of the hindgut digesta and intestinal morphology in early weaned pigs were examined. For these experiments, wheat bran (WB) was used as fibre source and loperamide as a drug (LOP) to increase the digesta transit time. In Expt 1, a total of 128 early weaned pigs were randomly distributed in a $2 \times 2$ factorial combination of WB inclusion $(0 v .40 \mathrm{~g} / \mathrm{kg})$ and LOP administration $(0 v .0 \cdot 07 \mathrm{mg} / \mathrm{kg}$ body weight $)$ during $13 \mathrm{~d}$. For Expt 2, a total of twenty-four piglets were allotted to three dietary treatments for $15 \mathrm{~d}$ with the same basal diet (control diet) as Expt 1; a diet with $80 \mathrm{~g} / \mathrm{kg}$ of WB and the combination of WB and LOP. In Expt 1, LOP improved the average daily feed intake and average daily gain of the animals $(P=0.001$ and $0 \cdot 007$, respectively). The same result was obtained when WB was combined with LOP. The WB-LOP group also showed a higher concentration of SCFA $(P=0.013)$, acetic acid $(P=0.004)$ and propionic acid $(P=0.093)$. On the other hand, WB inclusion reduced the organic matter and crude protein digestibility $(P=0.001)$ and tended to decrease the enterobacteria population $(P=0.089)$. In Expt 2 , WB increased the butyric acid concentration $(P=0.086)$. We concluded that the inclusion of WB to modify the intestinal microbiota activity combined with LOP may be beneficial to animal health and performance.
\end{abstract}

Wheat bran: Loperamide: Microbiota: Piglets: Digesta transit time

Weaning is a critical phase for piglets; it is associated with a variable period of anorexia during the first days after weaning, the deterioration of the digestive function and accumulation of undigested feed as a result of inefficient digestion ${ }^{(1)}$. During this period, piglets are more susceptible to suffer post-weaning diarrhoea, with the proliferation and attachment to the intestinal mucosa of B-haemolytic strains of Escherichia coli ${ }^{(2)}$. Previous studies have demonstrated that adding sources of dietary fibre in the piglet diets may reduce post-weaning diarrhoea $^{(3)}$.

There is a physiological rationale to support the addition of dietary fibre to young animals. Fermentable carbohydrates constitute the major energy source for microbial fermentation and therefore may act as a link between the piglet and its enteric commensal microbiota ${ }^{(4)}$. Adding dietary fibre into the diet can reduce the protein fermentation in the digesta ${ }^{(5)}$, and may normalise the colonic function and the small intestine and colonic mucosa architecture. However, there is conflicting evidence whether NSP promotes a beneficial effect or a detrimental effect on pig health. Thus, some studies have demonstrated that adding sources of mostly insoluble or slowly fermentable $\mathrm{NSP}^{(6)}$ or soluble NSP that do not increase viscosity $^{(7)}$ reduce infection-associated symptoms and enhance intestinal structure and function. On the other hand, diets containing soluble NSP sources, which promote increases in the digesta viscosity, such as pearl barley or guar gum, were associated with increased incidence of enteric disorders ${ }^{(8)}$

In earlier studies, we observed that adding wheat bran (WB) in the diet of weaned piglets promoted a beneficial shift in the microbial colonisation of the digestive tract, with a higher production of butyrate in the large intestine and lower enterobacteria counts in the colonic digesta ${ }^{(3)}$ and intestinal mucosa ${ }^{(9)}$. The WB is a source of insoluble NSP that is fairly resistant to microbial degradation in the gastrointestinal tract (GIT) of monogastric animals and reduces the digesta transit time in the small and large bowel ${ }^{(10,11)}$. We suggested that fermentable carbohydrates from WB were likely influencing bacterial cell growth and activity. However, we were not able to exclude that other changes on the physico-chemical properties of digesta or the digesta kinetics might have a role on the changes observed on the intestinal microbial populations. It might be hypothesised that WB might normalise

Abbreviations: ADG, average daily gain; BW, body weight; CP, crude protein; CT, control diet; FM, fresh matter; GIT, gastrointestinal tract; LOP, loperamide; MTT, minimum transit time; OM, organic matter; WB, wheat bran; WRC, water retention capacity.

* Corresponding author: Dr José Francisco Pérez, fax +34 935811494, email josefrancisco.perez@uab.es 
the digestive function and reduce enterobacteria counts by stimulating fermentation and the propulsive digestive motility. In this respect, butyrate, which is considered the main oxidative fuel for colonocytes, is known to increase with decreased digesta transit time in the $\mathrm{GIT}^{(12)}$ or by higher dilution rates in vitro ${ }^{(13)}$.

We designed the present studies to elucidate the role of the digesta transit time in the gut health. To this end we used loperamide (LOP) as a drug to increase digesta transit time. LOP works by decreasing peristalsis and fluid secretion, resulting in longer gastrointestinal transit time and increased absorption of fluids and electrolytes from the $\mathrm{GIT}^{(14)}$. It has been used extensively to delay the oro-caecal transit time in human studies ${ }^{(15)}$, in rats ${ }^{(16)}$ and also in pigs ${ }^{(17)}$. With the present study, we aimed to confirm the likely beneficial effects of including WB in the diet of early weaned piglets and to assess which, if any, of the productive, digestive or microbial effects of WB are dominant in changing the digesta transit time.

\section{Material and methods}

\section{Animals and housing}

Two experiments were performed at the Animal Facilities of the Universitat Autònoma de Barcelona and received prior approval from the Animal Protocol Review Committee of this institution. The treatment, management, housing, husbandry and slaughtering conditions conformed to the European Union Guidelines ${ }^{(18)}$. In Expt 1, a total of 128 commercial crossing piglets ((Large White $\times$ Landrace $) \times$ Pietrain $)$, which had been excluded from receiving creep feed, were weaned at the age of $24 \mathrm{~d}$ with an average body weight (BW) of 6.4 (SEM 1.17) kg. Pigs were transported from a commercial farm to the animal facilities and placed into thirty-two pens (four animals per pen). Each pen had a feeder and a water nipple to ensure ad libitum feeding and free water access. The pens were allotted to four treatments (eight replicates for each treatment, Table 1) in a $2 \times 2$ factorial design that included two levels of WB in the diet $(0 v .40 \mathrm{~g} / \mathrm{kg}$, control diet (CT) $v$. WB, respectively) and two levels of LOP administration ( 0 or $0.07 \mathrm{mg} / \mathrm{kg} \mathrm{BW}$, named $0 v$. LOP, respectively). For Expt 2, a total of twenty-four piglets of 7.4 (SEM 1.17) kg from the same origin, breed and age as the previous one were randomly distributed into twelve pens (two animals per pen). The pens were allotted to three treatments (Table 1) that included the same basal diet (CT) as Expt 1; but was modified by adding $8 \%$ of $\mathrm{WB}$ and adding WB with LOP (0.07 mg/kg BW, LOP).

\section{Experimental procedures and sampling}

In Expt 1, animals received the diets from the first day of the experiment until day 13. LOP (Fortasec ${ }^{\circledR}$, Esteve, Barcelona, Spain) was administered every morning to the LOP group at a dose of $0.07 \mathrm{mg} / \mathrm{kg} \mathrm{BW}$ as an oral solution $(0.2 \mathrm{mg} / \mathrm{ml}$ LOP). The rest of the animals received the same dose of water. The solutions were carefully administered by a $5 \mathrm{ml}$ plastic syringe fitted with an oesophageal tube. Two experimental periods $(0-7$ and $7-13 \mathrm{~d})$ were selected to register individual $\mathrm{BW}$, pen feed consumption and piglet health status. On day $10,0.15 \%$ of chromic oxide was added in the diet to determine the total tract apparent digestibility. On day 12 , faeces samples were taken to determine the $\mathrm{Cr}$ and SCFA concentrations, and lactobacilli and enterobacteria counts. On day $12,0.25 \%$ of ferric oxide was also included in the diet to determine the minimum transit time (MTT), which is defined as the time between the administration and the appearance of the red marker in the faeces per pen ${ }^{(19)}$. For Expt 2 all the animals received the experimental diets during $15 \mathrm{~d}$. On day 15 , animals were euthanised with an intravenous injection of sodium pentobarbital $(200 \mathrm{mg} / \mathrm{kg} \mathrm{BW})$. Animals were bled, and the abdomen was immediately opened to tie and remove the whole GIT. Samples from the colon consisted of a pool of all colonic contents. Half of the collected samples were freeze-dried and then dried at $103^{\circ} \mathrm{C}$

Table 1. Diet composition and chemical analysis

\begin{tabular}{|c|c|c|c|c|}
\hline \multirow[b]{2}{*}{ Diet } & \multicolumn{2}{|c|}{ Trial 1} & \multicolumn{2}{|c|}{ Trial 2} \\
\hline & CT & WB & CT & WB \\
\hline \multicolumn{5}{|l|}{ Raw ingredients $(\mathrm{g} / \mathrm{kg})$} \\
\hline Maize & $332 \cdot 1$ & $290 \cdot 3$ & $331 \cdot 1$ & $280 \cdot 0$ \\
\hline Barley & 211.6 & $210 \cdot 0$ & $238 \cdot 2$ & $210 \cdot 0$ \\
\hline Whey powder & $130 \cdot 0$ & $130 \cdot 0$ & $130 \cdot 0$ & $130 \cdot 0$ \\
\hline High fat whey & $100 \cdot 0$ & $100 \cdot 0$ & $100 \cdot 0$ & $100 \cdot 0$ \\
\hline Soya protein & $90 \cdot 0$ & $90 \cdot 0$ & $92 \cdot 5$ & $87 \cdot 1$ \\
\hline Wheat gluten & $58 \cdot 1$ & $55 \cdot 7$ & $30 \cdot 0$ & $30 \cdot 0$ \\
\hline Fish meal $\mathrm{LT}^{\star}$ & $40 \cdot 0$ & $40 \cdot 0$ & $40 \cdot 0$ & $40 \cdot 0$ \\
\hline Wheat bran & - & $40 \cdot 0$ & - & $80 \cdot 0$ \\
\hline Sunflower oil & - & $6 \cdot 5$ & - & 6.5 \\
\hline Dicalcium phosphate & $10 \cdot 3$ & $9 \cdot 6$ & $9 \cdot 1$ & 8.4 \\
\hline Calcium carbonate & $9 \cdot 3$ & $9 \cdot 7$ & $11 \cdot 7$ & $10 \cdot 6$ \\
\hline L-Lys $\mathrm{HCl}$ & $6 \cdot 8$ & $6 \cdot 7$ & $5 \cdot 2$ & $5 \cdot 2$ \\
\hline DL-Met & 1.5 & 1.5 & $4 \cdot 1$ & $4 \cdot 1$ \\
\hline L-Thr & $2 \cdot 1$ & $2 \cdot 1$ & $2 \cdot 3$ & $2 \cdot 3$ \\
\hline L-Trp & 0.7 & 0.7 & 0.6 & 0.6 \\
\hline Vitamin and mineral premix $\dagger$ & $4 \cdot 0$ & $4 \cdot 0$ & $5 \cdot 0$ & $5 \cdot 0$ \\
\hline Salt & 3.4 & $3 \cdot 3$ & - & - \\
\hline Chromic oxide & - & - & 0.15 & 0.15 \\
\hline \multicolumn{5}{|l|}{$\begin{array}{l}\text { Calculated composition } \\
\text { (g/kg as fed })\end{array}$} \\
\hline ME (MJ/kg) & $14 \cdot 6$ & $14 \cdot 6$ & 14.4 & $14 \cdot 3$ \\
\hline $\mathrm{CP}$ & $208 \cdot 8$ & $209 \cdot 1$ & $189 \cdot 6$ & $190 \cdot 9$ \\
\hline SID Lys & $13 \cdot 75$ & 13.71 & $12 \cdot 14$ & $12 \cdot 12$ \\
\hline SID Met & $4 \cdot 84$ & $4 \cdot 79$ & 6.94 & $6 \cdot 91$ \\
\hline SID Thr & $8 \cdot 72$ & $8 \cdot 68$ & $8 \cdot 28$ & $8 \cdot 23$ \\
\hline SID Trp & $2 \cdot 67$ & $2 \cdot 67$ & $2 \cdot 27$ & $2 \cdot 29$ \\
\hline SID Ile & $7 \cdot 77$ & $7 \cdot 73$ & $7 \cdot 02$ & $6 \cdot 96$ \\
\hline SID Val & $9 \cdot 07$ & $9 \cdot 05$ & $8 \cdot 3$ & $8 \cdot 26$ \\
\hline \multicolumn{5}{|l|}{$\begin{array}{l}\text { Chemical analysis } \\
\text { (g/kg as fed) }\end{array}$} \\
\hline $\mathrm{DM}$ & $908 \cdot 2$ & $907 \cdot 6$ & 903.0 & $903 \cdot 0$ \\
\hline GE (MJ/kg) & $17 \cdot 1$ & $17 \cdot 5$ & $17 \cdot 8$ & $17 \cdot 7$ \\
\hline $\mathrm{CP}(\mathrm{N} \times 6.25)$ & $200 \cdot 8$ & $205 \cdot 6$ & $208 \cdot 0$ & $210 \cdot 8$ \\
\hline Neutral-detergent fibre & $74 \cdot 0$ & $87 \cdot 0$ & $85 \cdot 3$ & $106 \cdot 3$ \\
\hline Acid-detergent fibre & $25 \cdot 0$ & $29 \cdot 0$ & $18 \cdot 9$ & 22.9 \\
\hline Diethyl ether extract & $67 \cdot 4$ & $80 \cdot 5$ & $71 \cdot 0$ & $75 \cdot 0$ \\
\hline Ash & $55 \cdot 0$ & $57 \cdot 0$ & $64 \cdot 0$ & $66 \cdot 0$ \\
\hline
\end{tabular}

$\mathrm{CT}$, control diet; WB, wheat bran diet; LT, low temperature; ME, metabolisable energy; CP, crude protein; SID, standardised ileal digestible; GE, gross energy.

* Fishmeal LT: product obtained by removing most of the water and some or all of the oil from fish by heating at low temperature $\left(<70^{\circ} \mathrm{C}\right)$ and pressing.

† Supplied per $\mathrm{kg}$ of feed: $5000 \mathrm{IU}(1500 \mu \mathrm{g})$ vitamin $\mathrm{A} ; 1000 \mathrm{IU}(25 \mu \mathrm{g})$ vitamin $\mathrm{D}_{3} ; 15.0 \mathrm{mg}$ vitamin $\mathrm{E} ; 1.3 \mathrm{mg}$ thiamine; $3.5 \mathrm{mg}$ riboflavin; $1.5 \mathrm{mg}$ pyridoxine; $0.025 \mathrm{mg}$ cyanocobalamin; $10.0 \mathrm{mg}$ calcium pantothenate; $15.0 \mathrm{mg}$ niacin; $15.0 \mathrm{mg}$ biotin; $0.1 \mathrm{mg}$ folic acid; $2.0 \mathrm{mg}$ vitamin $\mathrm{K}_{3} ; 80.0 \mathrm{mg} \mathrm{Fe} ; 6.0 \mathrm{mg} \mathrm{Cu} ; 0.7 \mathrm{mg}$ Co; $60.0 \mathrm{mg} \mathrm{Zn;} 30.0 \mathrm{mg} \mathrm{Mn;} 0.7 \mathrm{mg}$ iodine; $0.1 \mathrm{mg}$ Se and $0.15 \mathrm{mg}$ etoxiquín as antioxidant (Capsoquin, Itpsa, Barcelona, Spain).

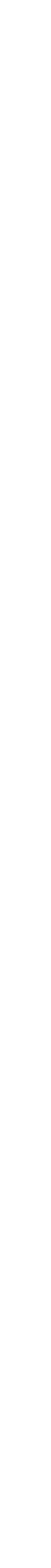


for complete water removal. The other half were divided into four aliquots: $3 \mathrm{~g}$ was collected into previously weighed $10 \mathrm{ml}$ screw cap tubes for water retention capacity (WRC) analysis; the remainder was collected in tubes for water swelling capacity; SCFA; microbial population. Finally, a section of $4 \mathrm{~cm}$ from mid-jejunum and $4 \mathrm{~cm}$ from the medium colon were removed, opened longitudinally and fixed by immersion in $10 \%(\mathrm{v} / \mathrm{v})$ buffered formalin for histological study.

\section{Analytical procedures}

Chemical analyses of the diets (Table 1) were performed according to the Association of Official Analytical Chemists $^{(20)}$ standard procedures. The chromium oxide concentration in feed and digesta was determined by atomic absorption spectrophotometry following the method of Williams et al. ${ }^{(21)}$. The WRC of fresh colon digesta contents was determined by centrifugation $(2500 \mathrm{~g} / 25 \mathrm{~min})$ following the method of Anguita et al. ${ }^{(22)}$; the water swelling capacity was determined as the ratio of liquid phase to solid phase obtained after allowing fresh colon digesta to stand for $3 \mathrm{~h}$ at room temperature in a test tube. DNA from faeces and colon was extracted and purified using the commercial QIAamp DNA Stool Mini Kit (Qiagen, West Sussex, UK) with some modifications as described by Castillo et al. ${ }^{(23)}$. Enterobacteria and lactobacilli were quantified by real time PCR using SyBR Green dye following the method of Castillo et al. ${ }^{(23)}$. The lactobacilli:enterobacteria ratio was calculated by subtracting $\log 16 \mathrm{~S}$ rDNA gene lactobacilli copies/g fresh matter (FM) minus log 16S rDNA gene enterobacteria copies/g FM. SCFA and lactic acid concentrations were determined by GC, after submitting the samples to an acid-base treatment followed by diethyl ether extraction and derivatisation, as described by Jensen \& Jørgensen ${ }^{(24)}$. Tissue samples for the histological study were dehydrated and embedded in paraffin wax, sectioned at $4 \mu \mathrm{m}$ and stained with haematoxylin and eosin. Morphometric measurements were performed with a light microscope (BHS, Olympus, Spain). Villus height and crypt depth, and the globet cell number in crypts were measured. Measurements were taken in ten well-oriented villi and crypts from each intestinal section of each animal. The villus height and crypt depth were measured using a linear ocular micrometer (Olympus, Ref. 209-35 040; Microplanet, Barcelona, Spain). On the basis of the cellular morphology, differences between globet cells and lymphocytes were clearly distinguishable at $400 \times$ magnification. Cell density was expressed as the number of lymphocytes per $1000 \mu^{2}$. All morphometric analyses were done by the same person, who was blind to the treatments.

\section{Statistical analyses}

In Expt 1, results on productive performance, microbial counts, organic matter (OM) and crude protein $(\mathrm{CP})$ digestibility, MTT and SCFA in the faeces were subjected to ANOVA using the generalized linear model procedure ${ }^{(25)}$. Data were analysed as a $2 \times 2$ factorial arrangement of treatments, with diet and LOP treatment as the factors in four randomised blocks. Productive performance data were adjusted for initial live weight by covariance analysis. In Expt 2, results on OM and starch digestibility, physico-chemical characteristics, SCFA and lactic acid and microbial population of the colonic digesta and morphometry of the intestinal mucosa were subjected to ANOVA with diet as the classification factor, using the generalized linear model procedure ${ }^{(25)}$. In both the experiments means presented in the tables are least square means, the pen was considered as the experimental unit. Differences were considered significant at $P<0.05$. Tendencies for $0.05<P<0.15$ were also presented.

\section{Results}

Expt 1

Animal performance, health status and nutrient digestibility. Data on feed intake and growth performance are shown in Table 2. The pigs receiving the LOP treatments showed a higher average daily feed intake $(P=0 \cdot 001)$ than animals without it. Differences were more pronounced in animals fed on the WB diet, reflecting the tendency in the interaction with

Table 2. Performance of pigs fed on the experimental diets early after weaning (Trial 1)

\begin{tabular}{|c|c|c|c|c|c|c|c|c|c|}
\hline \multirow[b]{3}{*}{ Item } & \multirow[b]{3}{*}{ Period } & \multicolumn{4}{|c|}{ Diets } & \multirow[b]{3}{*}{ SEM $(n 8)$} & \multirow{2}{*}{\multicolumn{3}{|c|}{$P$-diet }} \\
\hline & & \multicolumn{2}{|c|}{$\mathrm{CT}$} & \multicolumn{2}{|c|}{ WB } & & & & \\
\hline & & 0 & LOP & 0 & LOP & & DIET & LOP & $\mathrm{D} \times \mathrm{L}$ \\
\hline \multirow[t]{2}{*}{ Body weight (g) } & Initial & 6430 & 6400 & 6390 & 6390 & 11.4 & 0.952 & 0.970 & 0.969 \\
\hline & Final & 8590 & 8850 & 8610 & 9630 & $12 \cdot 8$ & 0.382 & 0.168 & 0.408 \\
\hline \multirow{3}{*}{$\begin{array}{l}\text { Average daily feed intake } \\
\text { (g/animal and d) }\end{array}$} & Week 1 & 189 & 221 & 183 & 248 & 33.3 & 0.408 & 0.001 & 0.210 \\
\hline & Week 2 & 354 & 382 & 328 & 424 & $50 \cdot 6$ & 0.660 & 0.001 & 0.070 \\
\hline & Overall & 271 & 293 & 253 & 325 & $37 \cdot 5$ & 0.610 & 0.001 & 0.069 \\
\hline \multirow{3}{*}{$\begin{array}{l}\text { Average daily gain } \\
\text { (g/animal and } d)\end{array}$} & Week 1 & 82 & 127 & 95 & 191 & $40 \cdot 0$ & 0.017 & 0.001 & 0.101 \\
\hline & Week 2 & 234 & 248 & 233 & 327 & 71.3 & 0.131 & 0.050 & 0.129 \\
\hline & Overall & $157^{\mathrm{b}}$ & $170^{\mathrm{b}}$ & $156^{\mathrm{b}}$ & $238^{a}$ & $47 \cdot 0$ & 0.050 & 0.007 & 0.047 \\
\hline \multirow[t]{3}{*}{ Gain:feed ratio } & Week 1 & 0.43 & 0.58 & 0.53 & 0.77 & 0.171 & 0.033 & 0.005 & 0.454 \\
\hline & Week 2 & 0.66 & 0.63 & 0.70 & 0.77 & 0.147 & 0.095 & 0.678 & 0.366 \\
\hline & Overall & 0.57 & 0.57 & 0.62 & 0.77 & 0.115 & 0.014 & 0.173 & 0.174 \\
\hline
\end{tabular}

CT, control diet; WB, wheat bran diet; LOP, loperamide; DIET, effect inclusion CT or WB in diet; $D \times L$, effect diet and loperamide treatment.

${ }^{a, b}$ Mean values within a row with unlike superscript letters were significantly different $(P<0.05)$. 
Table 3. Mortality, pigs with diarrhoea per treatment and coefficient of total tract apparent organic matter and crude protein digestibility in early weaned pigs (Trial 1 )

\begin{tabular}{|c|c|c|c|c|c|c|c|c|c|}
\hline \multirow[b]{3}{*}{ Item } & \multirow[b]{3}{*}{ Period } & \multicolumn{4}{|c|}{ Diets } & \multirow[b]{3}{*}{ SEM $(n 8)$} & \multirow{2}{*}{\multicolumn{3}{|c|}{$P$-diet }} \\
\hline & & \multicolumn{2}{|c|}{ CT } & \multicolumn{2}{|c|}{ WB } & & & & \\
\hline & & 0 & LOP & 0 & LOP & & DIET & LOP & $D \times L$ \\
\hline \multicolumn{10}{|c|}{ Animal health status (no. of pigs) } \\
\hline Mortality & Overall & $2 / 32$ & $2 / 32$ & 2/32 & $1 / 32$ & 0.44 & 0.690 & 0.690 & 0.690 \\
\hline Pigs with diarrhoea & Overall & $9 / 30$ & $8 / 30$ & $13 / 31$ & $4 / 32$ & 0.24 & 0.969 & 0.029 & 0.096 \\
\hline \multicolumn{10}{|c|}{ Total tract apparent digestibility } \\
\hline Organic matter & Final & $83 \cdot 2$ & 83.7 & $72 \cdot 0$ & $78 \cdot 0$ & $6 \cdot 75$ & 0.001 & 0.061 & 0.116 \\
\hline Crude protein & Final & 83.8 & 84.6 & $68 \cdot 7$ & $76 \cdot 0$ & 6.96 & 0.001 & 0.026 & 0.074 \\
\hline
\end{tabular}

WB and LOP during the second week $(P=0 \cdot 070)$ and the overall period $(P=0.069)$. A significant effect of the experimental treatments was also observed for the average daily gain (ADG) of the animals during weeks 1 and 2 after weaning. LOP and WB increased the ADG of the animal, with LOP pigs fed on the WB diet showing a much larger increase in ADG than the rest of the experimental treatments (interaction between $\mathrm{WB}$ and LOP, $P=0.047$ ). As a result of differences on the average daily feed intake and the ADG, pigs fed on the WB diet increased the feed efficiency $(P=0 \cdot 013)$ during the 2 -week period, while LOP administration increased feed efficiency during week $1(P=0 \cdot 005)$.

Table 3 shows the number of pigs with diarrhoea and the mortality rate, as well as the total tract apparent digestibility of $\mathrm{OM}$ and $\mathrm{CP}$. The LOP treatment reduced the number of pigs suffering diarrhoea $(P=0.029)$. This effect was essentially observed with the WB diet (tendency for an interaction, $P=0$-096). However, no significant differences in the mortality were observed between treatments. The incorporation of WB in the diet reduced the total tract digestibility of $\mathrm{OM}$ $(P=0 \cdot 001)$ and CP $(P=0 \cdot 001)$. On the other hand, LOP tended to improve the coefficient of OM $(P=0 \cdot 061)$ and improved the $\mathrm{CP}(P=0 \cdot 026)$ digestibility, especially with the WB diets $(P$ interaction $=0.074$ and 0.116 for $\mathrm{CP}$ and $\mathrm{OM}$ digestibility, respectively). No significant differences among diets were observed in the MTT registered on day 13 after weaning, averaging 13.7, 15.5, 13.4 and 14.4 hours for the CT-0, CT-LOP, WB-0 and WB-LOP treatments, respectively. However, LOP tended $(P=0.070)$ to increase the MTT compared with the non-treated animals.

Fermentation end products and quantitative changes in the microbial population of faeces. Total SCFA concentration and microbial counts in faeces are shown in Table 4. A significant interaction was observed between $\mathrm{WB}$ and LOP groups $(P=0.013)$ on the total SCFA concentration. The LOP administration increased the faecal SCFA concentration in piglets fed on the WB diet, whereas no differences were observed in the CT group. LOP treatment increased the concentration of acetic acid $(P=0.004)$ and tended to increase the propionic acid $(P=0.093)$ in piglets fed on the WB diet and increased $(P=0.009)$ the butyric acid in both the groups of animals (CT and WB). On the other hand, piglets fed on the WB diets tended to reduce $(P=0.062)$ concentration of isoacids. The piglets fed on the WB diet tended $(P=0.089)$ also to show lower counts of enterobacteria in the faeces compared with the CT diet. No significant differences were observed in the lactobacilli counts or associated with the LOP treatment.

Table 4. Concentration of SCFA and bacterial population (enterobacteria and lactobacilli) on faeces of piglets, $13 \mathrm{~d}$ after weaning (Trial 1)

\begin{tabular}{|c|c|c|c|c|c|c|c|c|}
\hline \multirow[b]{3}{*}{ Item } & \multicolumn{4}{|c|}{ Diets } & \multirow[b]{3}{*}{ SEM $(n 8)$} & \multirow{2}{*}{\multicolumn{3}{|c|}{$P$-diet }} \\
\hline & \multicolumn{2}{|c|}{ CT } & \multicolumn{2}{|c|}{ WB } & & & & \\
\hline & 0 & LOP & 0 & LOP & & DIET & LOP & $D \times L$ \\
\hline \multicolumn{9}{|c|}{ Concentration $(\mu \mathrm{mol} / \mathrm{g} \mathrm{FM})$ of SCFA } \\
\hline Total SCFA & $103 \cdot 0^{\mathrm{a}, \mathrm{b}}$ & $102 \cdot 2^{a, b}$ & $90 \cdot 9^{\mathrm{b}}$ & $114 \cdot 8^{\mathrm{a}}$ & $18 \cdot 35$ & 0.642 & 0.021 & 0.013 \\
\hline Acetic & $66 \cdot 1^{\mathrm{a}, \mathrm{b}}$ & $63 \cdot 3^{\mathrm{a}, \mathrm{b}}$ & $57 \cdot 1^{\mathrm{b}}$ & $73 \cdot 3^{\mathrm{a}}$ & $11 \cdot 85$ & 0.641 & 0.037 & 0.004 \\
\hline Propionic & $22 \cdot 2$ & $22 \cdot 1$ & 19.9 & 23.5 & 4.106 & 0.454 & 0.109 & 0.093 \\
\hline Butyric & 8.9 & $10 \cdot 5$ & $8 \cdot 8$ & $11 \cdot 7$ & 3.147 & 0.625 & 0.009 & 0.401 \\
\hline Isoacids & 3.5 & 3.9 & $2 \cdot 8$ & $3 \cdot 1$ & 1.436 & 0.062 & 0.384 & 0.824 \\
\hline Branched chain ratio & 0.035 & 0.041 & 0.034 & 0.031 & 0.0142 & 0.189 & 0.769 & 0.263 \\
\hline \multicolumn{9}{|c|}{ Bacterial population measured by real-time PCR (log $16 \mathrm{~S}$ rDNA gene copies/g FM) } \\
\hline Enterobacteria & 9.0 & $9 \cdot 3$ & $8 \cdot 8$ & 8.5 & 0.68 & 0.089 & 0.965 & 0.295 \\
\hline Lactobacilli & 9.6 & 9.4 & 9.4 & $9 \cdot 1$ & 0.46 & 0.291 & 0.216 & 0.818 \\
\hline
\end{tabular}

CT, control diet; WB, wheat bran diet; LOP, loperamide; DIET, effect inclusion CT or WB in diet; $\mathrm{D} \times \mathrm{L}$, effect diet and loperamide treatment.

${ }^{a, b}$ Mean values within a row with unlike superscript letters were significantly different $(P<0.05)$. 


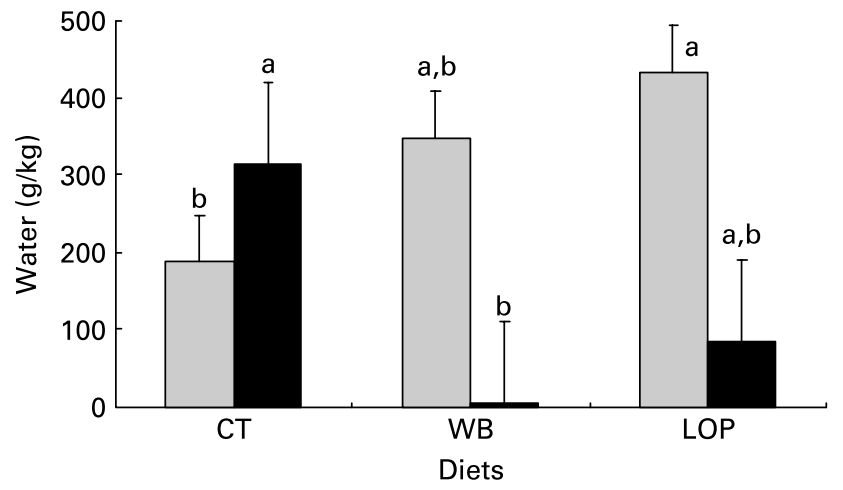

Fig. 1. Water retention capacity (WRC; $\square$ ) and unbound water $(\boldsymbol{\square})$ of colonic digesta in piglets fed experimental diets (Trial 2). Diets: CT, control diet; WB, wheat bran diet; LOP, animals treated with loperamide. Values are least square means ( $n$ 4), with standard errors represented by vertical bars. ${ }^{\mathrm{a}, \mathrm{b}}$ Mean values with unlike letters were significantly different $(P<0.05)$. The $P$-value for diet was 0.001 for the WRC and 0.018 for the unbound water.

\section{Expt 2}

Digestion and morphometry of the intestinal mucosa. LOP increased $(P=0.010)$ the digestibility of OM (data not shown). LOP also promoted significant changes in the morphometry of the jejunum, with an increase $(P=0.031)$ in the villus height:crypt depth ratio compared with the WB diet (data not shown). No other significant differences were observed in any of the variables studied in the jejunum. In the colon no significant differences were observed among the dietary treatments in the morphometric and the cellular measurements.

Physicochemical characteristics, fermentation parameters and microbial population of the colonic digesta. Data related to the physico-chemical characteristics of digesta (WRC and unbound water) are presented in Fig. 1. Feeding animals with WB diet and LOP administration increased $(P=0.001)$ the WRC compared with the CT diet. On the other hand, animals fed on the WB diet showed the lowest concentration $(P=0.018)$ of unbound water compared with the CT diet. No significant differences between treatments were observed on the total concentration of SCFA and the concentration of acetic, propionic, isoacids and lactic acid (data not shown). On the other hand, the butyric acid concentration tended $(P=0.086)$ to be higher in pigs fed on the WB diet $(35.9$ and $20.3 \mu \mathrm{mol} / \mathrm{g}$ FM for the WB and the WB-LOP groups, respectively) compared with the $\mathrm{CT} \operatorname{diet}(11.7 \mu \mathrm{mol} / \mathrm{g} \mathrm{FM})$. No significant differences were observed on the enterobacteria and lactobacilli counts (data not shown).

\section{Discussion}

The influence of wheat bran on the adaptation of piglets after weaning

Dietary fibre has become one of the dietary components, which has attracted much interest in connection with the nutrition of young animals. Previous studies have demonstrated that adding sources of mostly insoluble low-fermentable NSP (such as oat bran) to the diets for weaned pigs can ameliorate the incidence of diarrhoea and the animal performance ${ }^{(6,26)}$. The basis for this protective effect is still uncertain, but the authors suggested that it could be related to changes in the numbers and metabolic activity of selected components of the intestinal microbiota.

The WB (the coarse outer membrane of the wheat kernel) was chosen for the present study because of its high proportion of NSP as insoluble cellulose and arabinoxylans ${ }^{(27)}$ and its large particle size. Our results show that pigs fed on the WB treatment showed a reduction in the total tract digestibility of the $\mathrm{OM}$ and $\mathrm{CP}$, but underwent an increase in the feed efficiency. Numerous reports indicate that dietary fibre reduces the total tract digestibility of protein and energy. In practice, fibrous diet components dilute the nutrient in feed because the NSP fraction is digested to a lower extent than other fractions, such as those of starch, CP or fat ${ }^{(28,29)}$. Moreover, changes in the physical characteristics of the intestinal contents due to the presence of specific fibre components may increase the viscosity, influence gastric emptying or slow the diffusion or mobility of enzymes, substrates and nutrients to the absorptive surface. The consequence is that fibre may reduce nutrient digestibility of $\mathrm{fat}^{(30)}$ or increase the endogenous nitrogen excretion ${ }^{(31)}$. This effect was quantitatively described by Le Goff et al. ${ }^{(32)}$. They found that the impact of the neutral-detergent fibre fraction on the digestibility coefficient of energy is significant, with approximately $0.1 \%$ reduction per $1 \mathrm{~g}$ neutral-detergent fibre/kg DM.

In the literature, it is also generally accepted that fibre in the growing pig diet may also reduce the voluntary intake and the BW gain of the animals. In the present study, the pigs fed on the WB diets did not lower their voluntary intake and even increased the gain:feed efficiency. Some authors ${ }^{(3,6,33)}$ have reported that moderate levels of WB or oats hulls in postweaning diets increased the feed consumption of pigs. The authors suggested that young piglets may have a minimum requirement of fibre for correct functioning of the digestive tract. However, we should not exclude the possibility that the increased weight gain efficiency observed in the present study could be due, at least in part, to the increased weight of the internal organs, possibly by a higher weight of the gut contents ${ }^{(34)}$.

Including WB in the diet reduced the branched-chain fatty acid concentration and tended to decrease the enterobacteria population in the faeces. Previous results from our group have also indicated that incorporation of WB to the diet also decreased the enterobacteria counts in the caecum digesta ${ }^{(3)}$ and the K88 E. coli attachment to the ileum mucosa after an experimental infection ${ }^{(9)}$. Although enterobacteria contain numerous species of bacteria, its reduction may indicate a beneficial shift in the composition of the microbial population. In this respect, different authors have demonstrated that the inclusion of fermentable carbohydrates in weanling diets may reduce the protein fermentation along the $\operatorname{GIT}^{(4,35)}$ being related with the reduction in isoacids observed here. Protein fermentation in the digestive tract is considered as a potential risk for dysbiosis and proliferation of pathogenic bacteria $^{(36)}$. Pigs fed on the WB diet tended also to show a higher concentration of butyric acid in the colon. In this respect, butyrate is considered an important metabolite because it is the principal oxidative fuel for the colonocytes and may have beneficial trophic effects on the inflamed caeco-colonic mucosa ${ }^{(13)}$. It is accepted that starch and bran from wheat or oat stimulate the formation of butyrate ${ }^{(37)}$, 
while xylans and pectin rich fractions are all associated with a related low formation of butyrate ${ }^{(38)}$.

On the other hand, fibre is also able to modify the physicochemical properties of digesta. WB, due to its high content of insoluble fibre, is known to improve constipation in human subjects $^{(39)}$ and reduces the mean retention time of digesta in the small intestine of pigs ${ }^{(11)}$. In the present study, we were not able to detect differences in the MTT with the WB supplementation, but we observed a significant increase in the WRC and a reduced percentage of unbound water in the colonic digesta. The results demonstrate the higher water-binding capacity of the insoluble long-chain NSP as compared with other compounds, such as starch or protein ${ }^{(22)}$. Moreover, these changes could suggest that the physicochemical properties of digesta could have a role in some GIT processes, such as the gastric emptying, the small intestine motility or the hindgut fermentation. Some reports have suggested that a coarse diet may modify the physico-chemical and microbial properties of digesta contents, with decreases in the survival level of some enterobacteria, such as Salmonella ${ }^{(40)}$. The authors speculated that processes in the foregut, such as distribution of $\mathrm{HCl}$ within the stomach content, is favoured when a diet has a coarse structure and a higher WRC, so that lower counts of Salmonella reach the small intestine.

\section{The influence of loperamide on the adaptation of piglets to the diet}

LOP is a synthetic opiate derivative frequently used as antidiarrhoeal drug in human subjects. It decreases the motility of the circular and longitudinal smooth muscles of the intestinal wall, slows down the flow entering the colon and stimulates colonic water absorption ${ }^{(41)}$. While LOP is widely used in adults, there has been concern about the safety of using this drug for young children and during the course of infectious diarrhoea. The contraindications in cases of invasive bacterial infections come from the risk of aggravating the symptoms per digesta stasis allowing bacterial translocation. Results from the present study indicate that LOP tended to increase the MTT along the GIT and increased the total tract and foregut digestibility of $\mathrm{OM}$ and $\mathrm{CP}$, especially with the WB diet. These results were associated with a significant increase in the villus height:crypt depth ratio in the jejunum (Expt 2), which is considered a useful criterion for estimating the digestive capacity in the small intestine ${ }^{(42)}$. In contrast, other authors have reported that LOP strongly inhibits pancreaticobiliary secretion (bilirubin and amylase), acting on the nerve supply to the pancreas and gallbladder ${ }^{(43,44)}$.

Treating animals with LOP also increased the average daily feed intake and the ADG during the first 2 weeks after weaning. LOP is known to affect not only the opioid receptors related to inhibition of intestinal motility, but also those related to analgesia that are present on the peripheral sensory nerves and is up-regulated during the development of inflammation $^{(45)}$. After weaning, the stresses that the animals suffer lead to a period of anorexia that may contribute to a local inflammation in their small intestine ${ }^{(46)}$. Moreover, the reduced enteral feeding during the first days after weaning is considered to be the cause of the impairment of the piglet gut barrier and the shortened villi. It appears that treating animals with LOP early after weaning may reduce the intestinal inflammation and improve the behaviour of the animal; this resulted in a higher feed consumption, weight gain and improved mucosa integrity. This is in good agreement with Bowden et al. ${ }^{(47)}$, who reported positive effects of anti-inflammatory analgesic drugs and muscarinic receptor blocking agents on appetite in the pig.

The increase in the digestibility of WB diets with LOP was also associated with a significant increase in the concentration of SCFA, acetic, propionic and butyric acids in the faeces, which likely result from an advanced maturation of the colonic digestive tract. Graham et al. ${ }^{(48)}$ and Le Goff et al. ${ }^{(32)}$ suggested that the fibre degrading capacity in the pig intestine increases with age, likely due to increases on the transit time and the metabolic activity of the microbiota.

\section{Conclusions}

The inclusion of a moderate level of an insoluble fibre ingredient such as WB that could modify the intestinal microbiota activity, together with a drug like LOP, that has effects on the intestinal motility and peripheral analgesia, to the postweaning diet, may have beneficial effects with regard to animal health and performance.

\section{Acknowledgements}

This research was supported by the Spanish CICYT (project AGL2005-07 438-C02-01). We thank the Ministerio de Educación, Cultura y Deporte, Spain for research fellowships. We also thank the Servei de Granges i Camps Experimentals de la UAB for its service and assistance during the experiment. There are no conflicts of interest statements between the authors. F. M. G., M. Y., A. G. de S. U., R. G. H., J. F. P. $H$. have participated in the research and in the writing of the manuscript. J. G. G. has participated in the writing of the manuscript.

\section{References}

1. Lalles JP, Bosi P, Smidt H, et al. (2007) Weaning - a challenge to gut physiologists. Livestock Sci 108, 82-93.

2. Fairbrother JM, Nadeau E \& Gyles CL (2005) Escherichia coli in postweaning diarrhea in pigs: an update on bacterial types, pathogenesis, and prevention strategies. Anim Health Res Rev 6, 17-39.

3. Molist F, Gómez de Segura A, Gasa J, et al. (2009) Effects of the insoluble and soluble dietary fibre on the physicochemical properties of digesta and the microbial activity in early weaned piglets. Anim Feed Sci Technol 149, 346-353.

4. Awati A, Williams BA, Bosch MW, et al. (2006) Effect of inclusion of fermentable carbohydrates in the diet on fermentation end-product profile in feces of weanling piglets. $J$ Anim Sci 84, 2133-2140.

5. Hermes RG, Molist F, Ywazaki M, et al. (2009) Effect of dietary level of protein and fiber on the productive performance and health status of piglets. J Anim Sci 87, 3569-3577.

6. Mateos GG, Martin F, Latorre MA, et al. (2007) Inclusion of oat hulls in diets for young pigs based on cooked maize or cooked rice. Anim Sci 82, 57-63.

7. Wellock IJ, Fortomaris PD, Houdijk JGM, et al. (2007) The consequences of non-starch polysaccharide solubility and inclusion level on the health and performance of weaned pigs challenged with enterotoxigenic Escherichia coli. Br J Nutr 99, 520-530. 
8. Hopwood DE, Pethick DW, Pluske JR, et al. (2004) Addition of pearl barley to a rice-based diet for newly weaned piglets increases the viscosity of the intestinal contents, reduces starch digestibility and exacerbates post-weaning colibacillosis. Br J Nutr 92, 419-427.

9. Molist F, Gómez de Segura A, Perez JF, et al. (2009) Effect of wheat bran on the health and performance of weaned pigs challenged with Escherichia coli $\mathrm{K}^{8} 8^{+}$. Livestock Sci (In the Press).

10. Cummings JH \& Stephen AM (1980) The role of dietary fiber in the human-colon. Can Med Assoc J 123, 1109-1114.

11. Wilfart A, Montagne L, Simmins H, et al. (2007) Digesta transit in different segments of the gastrointestinal tract of pigs as affected by insoluble fibre supplied by wheat bran. Br J Nutr 98, 54-62.

12. Lewis SJ \& Heaton KW (1997) Increasing butyrate concentration in the distal colon by accelerating intestinal transit. Gut 41, 245-251.

13. Oufir LE, Barry JL, Flourie B, et al. (2000) Relationships between transit time in man and in vitro fermentation of dietary fiber by fecal bacteria. Eur J Clin Nutr 54, 603-609.

14. Baker DE (2007) Loperamide: a pharmacological review. Rev Gastr Dis 7, S11-S18.

15. Stephen AM, Wiggins HS \& Cummings JH (1987) Effect of changing transit-time on colonic microbial-metabolism in man. Gut 28, 601-609.

16. Mittelstadt S, Hemenway C \& Spruell R (2005) Effects of fasting on evaluation of gastrointestinal transit with charcoal meal. J Pharmacol Toxicol Meth 52, 154-158.

17. Awouters F, Megens A, Verlinden M, et al. (1993) Loperamide - survey of studies on mechanism of its antidiarrheal activity. Dig Dis Sci 38, 977-995.

18. The Council of the European Communities (1986) Council Directive 86/609/EEC of 24 November 1986 on the approximation of laws, regulations and administrative provisions of the Member States regarding the protection of Animals used for Experimental and Scientific purposes. http://europa.eu.int/ comm/environment/chemicals/lab_animals/legislation_en.htm (accessed 25 April 2006).

19. Castle EJ \& Castle ME (1956) The rate of passage of food through the alimentary tract of pigs. J Agric Sci 47, 196-203.

20. AOAC (1995) In Official Methods of Analysis [Association of Official Analytical Chemists, editors]. Arlington, VA: USA.

21. Williams CH, Iismaa O \& David DJ (1962) Determination of chromic oxide in faeces samples by atomic absorption spectrophotometry. J Agric Sci 59, 381-385.

22. Anguita M, Gasa J, Nofrarias M, et al. (2007) Effect of coarse ground corn, sugar beet pulp and wheat bran on the voluntary intake and physicochemical characteristics of digesta of growing pigs. Livestock Sci 107, 182-191.

23. Castillo M, Martin-Orue SM, Roca M, et al. (2006) The response of gastrointestinal microbiota to avilamycin, butyrate, and plant extracts in early-weaned pigs. J Anim Sci 84, 2725-2734.

24. Jensen BB \& Jørgensen H (1994) Effect of dietary fiber on microbial activity and microbial gas-production in various regions of the gastrointestinal-tract of pigs. Appl Environ Microbiol 60, 1897-1904.

25. SAS Inc. (1999) SAS ${ }^{\circledR}$ User's Guide: Statistics. Cary, NC: SAS Inc.

26. Kim JC, Mullan BP, Hampson DJ, et al. (2008) Addition of oat hulls to an extruded rice-based diet for weaner pigs ameliorates the incidence of diarrhoea and reduces indices of protein fermentation in the gastrointestinal tract. Br J Nutr 99, $1217-1225$

27. Knudsen KEB (1997) Carbohydrate and lignin contents of plant materials used in animal feeding. Anim Feed Sci Technol 67, 319-338.

28. Morales J, Perez JF, Baucells MD, et al. (2002) Comparative digestibility and lipogenic activity in Landrace and Iberian finishing pigs fed ad libitum corn- and corn-sorghum-acorn-based diets. Livestock Prod Sci 77, 2-3.

29. Knudsen KEB, Serena A, Kjaer AKB, et al. (2005) Rye bread enhances the production and plasma concentration of butyrate but not the plasma concentrations of glucose and insulin in pigs. J Nutr 135, 1696-1704.

30. Freire JPB, Guerreiro AJG, Cunha LF, et al. (2000) Effect of dietary fibre source on total tract digestibility, caecum volatile fatty acids and digestive transit time in the weaned piglet. Anim Feed Sci Technol 87, 71-83.

31. Schulze H, Vanleeuwen P, Verstegen MWA, et al. (1995) Dietary level and source of neutral detergent fiber and ileal endogenous nitrogen flow in pigs. J Anim Sci 73, 441-448.

32. Le Goff G, van Milgen J \& Noblet J (2002) Influence of dietary fibre on digestive utilization and rate of passage in growing pigs, finishing pigs and adult sows. Anim Sci 74, 503-515.

33. Kyriazakis I, Emmans GC \& Anderson DH (1995) Do breeds of pig differ in the efficiency with which they use a limiting protein supply? Br J Nutr 74, 183-195.

34. Pond WG, Pond KR, Ellis WC, et al. (1986) Markers for estimating digesta flow in pigs and the effects of dietary fiber. J Anim Sci 63, 1140-1149.

35. Bikker P, Dirkzwager A, Fledderus J, et al. (2006) The effect of dietary protein and fermentable carbohydrates levels on growth performance and intestinal characteristics in newly weaned piglets. J Anim Sci 84, 3337-3345.

36. Prohaszka L \& Baron F (1980) The predisposing role of high dietary protein supplies in enteropathogenic Escherichia coli infections of weaned pigs. Zentralbl Veterinarmed B 27, 222-232.

37. Bugaut M (1987) Occurrence, absorption and metabolism of short chain fatty acids in the digestive tract of mammals. Comp Bioch Physiol 86, 439-472.

38. Hughes SA, Shewry PR, Li L, et al. (2007) In vitro fermentation by human fecal microflora of wheat arabinoxylans. J Agric Food Chem 55, 4589-4595.

39. Cann PA, Read NW \& Holdsworth CD (1984) What is the benefit of coarse wheat bran in patients with irritable bowel syndrome? Gut 25, 168-173.

40. Mikkelsen LL, Naughton PJ, Hedemann MS, et al. (2004) Effects of physical properties of feed on microbial ecology and survival of Salmonella enterica serovar Typhimurium in the pig gastrointestinal tract. Appl Environ Microbiol 70, 3485-3492.

41. Schiller LR, Ana CAS, Morawski SG, et al. (1984) Mechanism of the antidiarrheal effect of loperamide. Gastroenterol 86, $1475-1480$.

42. Montagne L, Pluske JR \& Hampson DJ (2003) A review of interactions between dietary fibre and the intestinal mucosa, and their consequences on digestive health in young non-ruminant animals. Anim Feed Sci Technol 108, 95-117.

43. Appia F, Chariot J, Roze C, et al. (1984) Loperamide induced inhibition of pancreatic secretion in rats. Eur J Pharmacol 103, 71-79.

44. Thimister PW, Hopman WP, van Roermund RF, et al. (1997) Inhibition of pancreaticobiliary secretion by loperamide in humans. Hepatology 26, 256-261.

45. Stein C, Machelska H \& Schafer A (2001) Peripheral analgesic and antiinflammatory effects of opioids. Z Rheumatol 60, 416-424.

46. McCracken BA, Spurlock ME, Roos MA, et al. (1999) Weaning anorexia may contribute to local inflammation in the piglet small intestine. J Nutr 129, 613-619.

47. Bowden HC, Sharman DF \& Stephens DB (1987) Effects of antiinflammatory analgesic drugs and muscarinic receptor blocking agents on appetite in the pig. $J$ Vet Pharmacol Ther 10, 269-272

48. Graham H, Hesselman K \& Aman P (1986) The influence of wheat bran and sugar-beet pulp on the digestibility of dietary components in a cereal based pig diet. J Nutr 116, 242-251. 